\title{
Covered self-expandable metallic stents in benign pyloric obstruction: long term results.
}

\author{
Gökhan Demiral ${ }^{1}$, Onur Bayraktar ${ }^{2}$, Salih Bölük ${ }^{3}$, Alp Özçelik ${ }^{4}$, İbrahim Ali Özemir ${ }^{5}$, Barış \\ Bayraktar6 \\ ${ }^{1}$ General Surgery Department, Recep Tayyip Erdogan University, Rize, Turkey \\ ${ }^{2}$ General Surgery Department, Atakent Hospital, Acibadem University, Istanbul, Turkey \\ ${ }^{3}$ General Surgery Department, Sancaktepe Training and Research Hospital, Istanbul, Turkey \\ ${ }^{4}$ General Surgery Department, Yalova Private Hospital, Yalova, Turkey \\ ${ }^{5}$ General Surgery Department, Goztepe Training and Research Hospital, Istanbul Medeniyet Unıversity, Turkey \\ ${ }^{6}$ General Surgery Department, Gebze Konak Hospital, Kocaeli, Turkey
}

\begin{abstract}
Background/aim: The Self-Expandable Metalic Stent (SEMS) was firstly used for treatment of malignant obstruction of the esophagus, pylorus and colon. Nowadays some recent studies has been documented the use of SEMS in Benign Pyloric Obstruction (BPO). In this study we aimed to evaluate the efficacy of covered SEMSs in BPO.

Method: A total 15 patients hospitalized with BPO and underwent SEMS between June 2012 and May 2016. Data were analysed retrospectively.

Results: Study was consisted of 6 female and 9 male patients with a median age of $55.4(27-73 \mathrm{y})$ and follow-up time of 42.7 (27-60 months). SEMS technically applied with success in all patients. BPO was due to peptic ulcer in 6 patients $(40 \%)$ and peptic ulcer perforation surgery in $9(60 \%)$. Gastric Outlet Obstruction Scoring System (GOSS) was used to assess symptom improvement. Significant symptomatic improvement was observed on $3^{\text {rd }}$ day with GOOSS 3 in twelve patients and GOOSS 2 in three patients after stenting. Also sixth month GOOSS scores were 3 in 12 patients (three patients were operated after stenting). Major complications was observed in four patients (26.7\%); stent migration in 2, perforation and bleeding in 1. Minor complications were gastoparesis and dyspepsia in 6 patients, abdominal pain in 2 , halitosis in 2 and hematemesis in 1 , and severe vomiting in 1. Two patients were symptom free $(\mathbf{1 3 . 3 \%})$. Helicobacter pylori test was positive after stenting and $\mathrm{Hp}$ eradication was applied to all patients.

Conclusion: Covered SEMS has the advantages of low complications, rapid improvement in obstructive symptoms and high patient compliance in BPO.
\end{abstract}

Keywords: Benign pyloric obstruction, Covered self-expandable metallic stent, Gastric outlet obstruction scoring system.

Accepted on April 27, 2018

\section{Introduction}

Benign Pyloric Obstruction (BPO) may be caused due to peptic ulcers, corosive injuries anastomotic strictures after gastric surgery, and strictures secondary to endoscopic interventions. Peptic ulcer disease is the most common cause of BPO [1]. Endoscopic Balloon Dilatation (EBD) is the first line treatment method and was introduced by Benjamin et al. in 1982 [2]. This procedure is relatively simple and preferred by patients and physicians. However immediate symptomatic reliefs were reported with variable controversial long term follow up results
[3-5]. On the other hand surgery may not be appropriate due to accompanying postoperative comorbidities in poor or elderly patients although it is the conventional treatment modality [6]. Therefore long-acting and less invasive treatment methods are needed. Self-Expandable Metallic Stent (SEMS) was originally developed for palliation of malignant obstructions of esophagus, pylorus and colon. Satisfactory results comparing to surgery were reported with these stents both for palliation or bridge to surgery [7-9]. Nowadays, some successful outcomes of SEMS in BPO have been reported in few studies $[10,11]$. 
This study is presented to reflect the evaluation of efficacy of covered SEMSs in BPO.

\section{Materials and Methods}

Covered SEMS insertion was performed totally in 15 patients with BPO between June 2012 and May 2016. We retrospectively analysed the data of these patients. Informed consent was obtained from all patients and study was approved by the ethics committee.

All these patients were presented to emergency department with obstructive symptoms of nausea, vomiting, abdominal bloating and pain. Conservative treatment did not heal the symptoms and upper gastrointestinal imaging with endoscopy was revealed the findings of pyloric stenosis. Tip of the gastroscope could not be passed through the pylorus. Histopathological examination was performed before the procedure. All patients were informed both for EBD and SEMS. Six patients preferred EBD and other nine patients (PUPS group) preferred SEMS as first line choice. Degree of obstructive symptoms one day prior and three days and six months after the stenting was assessed by using Gastric Outlet Obstruction Scoring System (GOOSS) (Table 1).

Table 1. Definition of gastric outlet obstruction scoring system.

\begin{tabular}{ll}
\hline Gooss- Gastric Outlet Obstruction \\
\hline \multicolumn{2}{c}{ scoring system } \\
\hline 1 & no oral intake \\
\hline 2 & liquids only \\
\hline 3 & lowt solids only \\
\hline
\end{tabular}

\section{Endoscopic technique}

The procedure was performed after pharyngeal anesthesia (with 10\% lidocaine spray) under sedation (midazolam 2-5 mg) in endoscopy unit. The endoscope (EPX-4400 HD; Fujinon, Tokyo, Japan) was passed through eosophagus to stomach with fluoroscopic guidance. The length of the stenotic segment was measured by catheter passing over the guidewire. Covered intestinal type SEMSs (Micro-Tech Europe GmbH, Düsseldorf, Germany) was used. The stents were $20 \mathrm{~mm}$ in diameter and 8 or $12 \mathrm{~cm}$ in length. A standard biliary catheter was passed through the pyloric segment following a biliary guidewire (Jagwire, Boston Scientific Co.). After passing the catheter through the stenotic segment, a water-soluble contrast (Gastrografin, Bracco Co.) was administered and the distal end of the stenotic segment was visualized under fluoroscopy. After placement, the position of stent was verified by direct abdominal X-ray.

Patients were allowed oral liquid intake $6 \mathrm{~h}$ after stenting. Abdominal plain radiography was applied to verify the position of stent and to detect potential early complications $24 \mathrm{~h}$ after the stenting. Also if there was no major complication, then oral intake was augmented from liquids to soft diet. Further followup after discharge was evaluated with fluoroscopic control at the outpatient clinic one month after the stenting and one week before stent removal.

If the patients had no feeding problems with a GOOSS score 3, removal of stent was planned at 6 to $8 \mathrm{w}$ after insertion with gastroscopic and fluoroscopic guidance. Patients were allowed to take liquids after SEMS removal and discharged 6 hours later. Control gastroscopy and barium graphy were performed within first month to observe the patency of the gastric outlet. Patients underwent surveillance endoscopy at $3^{\text {rd }}$ and $6^{\text {th }}$ months.

\section{Results}

This study was consisted of 6 female and 9 male patients with a mean age of 55.4 (range, 27-73 y). The reason of stenosis was peptic ulcer (PU) in six patients and Peptic Ulcer Perforation Surgery (PUPS) in nine patients. In PU group, stenotic segment includes only Pylorus $(\mathrm{P})$ in five patients, and both $\mathrm{P}$ and Bulbus Duodeni (BD) in one patient. In PUPS group, stenotic segment was in $\mathrm{P}$ in five patient and both $\mathrm{P}$ and $\mathrm{BD}$ in four. The previous surgery was Graham's Patch (GP) procedure in PUPS group.

Eight $\mathrm{cm}$ stents were used for pyloric obstructions and $12 \mathrm{~cm}$ stents were used for pyloric and duodenal stenosis. All six PU patients underwent EBD prior to SEMS insertion (Table 2). Median follow-up time was 42.7 (range, 27-60 months). SEMSs were technically applied with success in all 15 patients. Median stenting time was 24.4 (18.2-32 min). Symptomatic improvement was assessed by GOOSS score. Prior to procedure, the scores of seven patients were 0 , and the others 1. Significant symptomatic improvement was observed on postinterventional $3^{\text {rd }}$ day with GOOSS 3 in twelve patients and GOOSS 2 in three patients. Three patients were (Patient 1, 4 and 13) operated after stenting for different reasons and GOOSS scores were 3 in non-operated twelve patients after 6 months (Table 3).

Table 2. The patients demographics (PU: Peptic Ulcer, PUPS: Peptic Ulcer Perforation Surgery, P: Pylorus, BD: Bulbus Duodeni, EBD: Endoscopic Ballon Dilatation).

\begin{tabular}{lll}
\hline Sex (female/male) & $6 / 9$ \\
\hline Age $(\mathrm{y})$ & $55.4(27-73)$ & \\
\hline Diagnosis & $6 \mathrm{PU}$ & $9 \mathrm{PUPS}$ \\
- Stricture region & $5 \mathrm{P} / 1 \mathrm{P}+\mathrm{BD}$ & $5 \mathrm{P} / 4 \mathrm{P}+\mathrm{BD}$ \\
\hline Median stenting time (min.) & $24.4(18.2-32)$ & \\
\hline Median follow up time (month) & $42.7(27-60)$ & \\
\hline EBD, prior to stenting & $6(40 \%)$ & \\
\hline
\end{tabular}


Covered self-expandable metallic stents in benign pyloric obstruction: long term results

Post-stent operation need $3(20 \%)$

Table 3. Detailed demographic data of the patients (M: Male, F: Female, PU: Peptic Ulcer, PUPS: Peptic Ulcer Perforation Surgery, GP: Graham Patch (prior operation), P: Pylorus, BD: Bulbus Duodeni; EBD: Endoscopic Ballon Dilatation; GOOSS: Gastric Outlet Obstruction Scoring System; DSGRYGJ: Distal Subtotal Gastrectomy and Roux-en-Y gastrojejunostomy).

\begin{tabular}{|c|c|c|c|c|c|c|c|c|}
\hline \multirow[t]{2}{*}{$\begin{array}{l}\text { Etiology } \\
\text { stenosis }\end{array}$} & \multirow[t]{2}{*}{ of } & \multirow[t]{2}{*}{ No } & \multirow[t]{2}{*}{ Age/Sex } & Stricture region & $\begin{array}{l}\text { EBD/GOOSS: } \\
\text { stenting/3 d } \begin{array}{r}\text { before } \\
\text { stenting }\end{array}\end{array}$ & \multirow[t]{2}{*}{ Complication } & \multirow[t]{2}{*}{$\begin{array}{l}\text { Stent } \\
\text { duration }(w)\end{array}$} & \multirow[t]{2}{*}{$\begin{array}{l}\text { Follow-up time } \\
\text { (month) }\end{array}$} \\
\hline & & & & $\begin{array}{l}\text { Stenotic length (Stent length- } \\
\text { diameter) }(\mathrm{cm})\end{array}$ & 6 months after stenting & & & \\
\hline \multirow[t]{12}{*}{ PU } & & 1 & $45 / \mathrm{M}$ & $\mathrm{P}+\mathrm{BD}$ & $+/ 0 / 3 /-$ & Gastroparesis and dyspepsia & 8 & 60 \\
\hline & & & & 12 & & $\begin{array}{l}\text { Peptic ulcer perforation on 3rd } \\
\text { month }\end{array}$ & & \\
\hline & & 2 & $53 / F$ & $\mathrm{P}$ & $+/ 0 / 3 / 3$ & - & 7 & 46 \\
\hline & & & & 8 & & & & \\
\hline & & 3 & $62 / F$ & $\mathrm{P}$ & $+/ 1 / 3 / 3$ & Gastroparesis and dyspepsia & 8 & 52 \\
\hline & & & & 8 & & & & \\
\hline & & 4 & $68 / \mathrm{M}$ & $\mathrm{P}$ & $+/ 1 / 3 /-$ & Stent migration on $3^{\text {rd }}$ week & 3 & 36 \\
\hline & & & & 8 & & DSGRYGJ on $1^{\text {st }}$ week & 1 & \\
\hline & & 5 & $72 / \mathrm{M}$ & $\mathrm{P}$ & $+/ 1 / 2 / 3$ & - & 6 & 54 \\
\hline & & & & 8 & & & & \\
\hline & & 6 & $67 / M$ & $\mathrm{P}$ & $+/ 1 / 3 / 3$ & Halitosis & 6 & 40 \\
\hline & & & & 8 & & & & \\
\hline \multirow[t]{18}{*}{ PUPS (GP) } & & 7 & $42 / F$ & $\mathrm{P}+\mathrm{BD}$ & $-/ 0 / 3 / 3$ & Severe vomiting & 6 & 38 \\
\hline & & & & 12 & & & & \\
\hline & & 8 & $27 / \mathrm{M}$ & $\mathrm{P}+\mathrm{BD}$ & $-/ 0 / 3 / 3$ & Hematemesis, bleeding & 8 & 40 \\
\hline & & & & 12 & & & & \\
\hline & & 9 & $69 / \mathrm{M}$ & $\mathrm{P}$ & $-/ 1 / 3 / 3$ & Gastroparesis and dyspepsia & 8 & 42 \\
\hline & & & & 8 & & & & \\
\hline & & 10 & $36 / \mathrm{M}$ & $\mathrm{P}+\mathrm{BD}$ & $-/ 0 / 3 / 3$ & & 7 & 45 \\
\hline & & & & 12 & & Abdominal pain & & \\
\hline & & 11 & $28 / F$ & $\mathrm{P}$ & $-/ 0 / 3 / 3$ & Gastroparesis and dyspepsia & & 36 \\
\hline & & & & 10 & & & & \\
\hline & & 12 & $62 / \mathrm{M}$ & $\mathrm{P}$ & $-/ 1 / 2 / 3$ & Abdominal pain & & 42 \\
\hline & & & & 8 & & & & \\
\hline & & 13 & $73 / F$ & $\mathrm{P}+\mathrm{BD}$ & $-/ 1 / 3 /-$ & $\begin{array}{l}\text { Stent migration on } 5^{\text {th }} \text { week } \\
\text { (GOOSS 1), restenosis and }\end{array}$ & 5 & 27 \\
\hline & & & & 12 & & $\begin{array}{l}\text { DSGRYGJ on } 10^{\text {th }} d \\
\text { gastroparesis and dyspepsia }\end{array}$ & & \\
\hline & & 14 & $65 / \mathrm{M}$ & $\mathrm{P}$ & $-/ 1 / 2 / 3$ & Halitosis & 8 & 35 \\
\hline & & & & 8 & & & & \\
\hline & & 15 & $66 / F$ & $\mathrm{P}$ & $-/ 0 / 3 / 3$ & Gastroparesis and dyspepsia & 8 & 48 \\
\hline & & & & 8 & & & & \\
\hline
\end{tabular}


Major complications were observed totally in four patients $(26 \%)$. Patient 1 was operated for peptic ulcer perforation at third month. The perforation was on the antrum. Gastroduodenal passage was normal and only GP procedure was performed. After third month, his GOOSS score was improved to 3. In Patient 4, there was concomitant huge gastric dilatation with atonic stomach prior to stenting and stent migration was observed during follow up on $3^{\text {rd }}$ week. This patient was presented with obstructive symptoms with GOOSS 1 , and an additional stent was applied. Then, severe vomiting resolving after nasogastric decompression was observed for three days. Because of recurrent obstructive symptoms, distal subtotal gastrectomy and Roux-en-Y gastrojejunostomy (DSGRYGJ) was performed one week after the restenting procedure. Another patient (Patient 8) was hospitalized for hematemesis due to bleeding. In endoscopic control, the source of bleeding was found at pylorus and resolved spontaneously after two days. In patient 13, stent migration was observed $5 \mathrm{w}$ after stenting with obstructive symptoms (GOOSS 1). Because of recurrent obstructive symptoms DSGRYGJ was performed $10 \mathrm{~d}$ after restenting. Postoperatively, there was gastoparesis and dyspepsia for $2 \mathrm{~W}$.

Oral intake of liquids was started within $6 \mathrm{~h}$ after stent placement in 13 patients. Two patients were suffered from severe abdominal pain (Patients 10 and 12), and one with severe vomiting (Patient 7) there was no any pathologic findings on CT scan. Oral intake was permitted to these patients after $24 \mathrm{~h}$. Dyspeptic complaints were observed on patients (Patients 1,3,9,11,13 and 15) due to gastroparesis and were treated with prokinetic agents (erythromycin and metoclopramide). In two patient (Numbers 6 and 14) halitosis occurred and resolved after one month. Helicobacter pylori test was positive in all patients after stenting and $\mathrm{Hp}$ eradication was applied to all patients.

\section{Discussion}

The TTS technique allows the physician to inspect the stenotic segment via endoscope and place SEMS at the targeted position [12,13]. SEMS has been introduced initially as palliative treatment for gastrointestinal tract malignancies. The use of SEMS in benign obstructions has rarely been reported [12-15]. Although, the most reports were relevant only with the esophageal lesions, including anastomotic stricture or achalasia $[16,17]$, recently several studies are reported about the use of SEMS in BPO. This method can also be preferred in patients having high surgical risks. It also has some additional advantages compared to surgery; the clinician more easily perform, the patient will suffer less and it is more comfortable for the patient $[10,14,16,18]$.

EBD has been preferred as the first line treatment method of BPO with favorable improvement of obstructive symptoms [19]. However quite different and incompatible results were reported about symptomatic relief. In a 21 patients study all patients were remained in symptomatic remission period during a follow-up time of 43 (5-90) months [4]. On the contrary in another study recurrence of symptoms were reported in 16 of 19 patients (84\%) during a 45 (25-96) months follow-up period [20]. In a prospective study, 14 of $42(33 \%)$ patients underwent surgery due to perforation during follow up period. The incidence of overall asymptomatic period decreases with the follow up time. Totally $85.3 \%$ of patients were asymptomatic at $12^{\text {th }}$ month and $68.8 \%$ at $48^{\text {th }}$ month [21]. Consequently, in the context of these studies we may suggest that there is a need for another modality with long term efficacy.

Dyspeptic complaints, abdominal bloating, nausea, vomiting and weight loss are common findings in BPO [22]. In a prospective study analysing efficacy of SEMS in BPO, Choi et al. reported immediate symptomatic improvement in 18 of the 22 patients $(81.8 \%)$, within $3 \mathrm{~d}$ after the process. This clinical improvement continued 6 to 8 weeks in 12 patients $(66.7 \%)$, without any symptoms (the mean follow-up time 10.2 months) (13). In our study the $3^{\text {rd }}$ day GOOSS; 2 in 3 patients, and 3 in 12 patients. In addition, the $6^{\text {th }}$ month GOOSS score was 3 in $12(80 \%)$ patients.

Some complications may occur during or after gastroduodenal stenting with SEMS [23-25]. Classification of complications is defined as early $(\leq 7 \mathrm{~d})$ and late $(>7 \mathrm{~d})$ in some reports and, as minor and major in others [23]. Sedation related complications, pain, nausea, vomiting, pulmonary aspiration, stent malposition, perforation and bleeding are early complications that may develop during or immediately after stenting [23]. Late complications are migration or occlusion of stent, fistula formation, perforation and bleeding. In a review study, major early and late complications are reported to occur in 7 to $18 \%$ respectively [24]. In another 606 patients systematic review bleeding and perforation were observed in seven patients $(1.2 \%)$ and stent migration in 31 patients $(5 \%)$ without any mortality. Stent obstruction was observed in 104 cases $(18 \%)$ mainly due to tumoral growth [23]. Pain, nausea and vomiting are not frequent complications (9\%) [24]. Some other studies also report the incidence of perforation and bleeding as $1 \%$ or less $[25,26]$. Complications in our study were as following in accordance with the literature gastroparesis in $6(40 \%)$ of 15 patient; migration, restenosis, abdominal pain and halitosis in 2 $(13.5 \%)$; and perforation and severe vomiting in $1(6.7 \%)$.

Covered SEMS is usually preferred to allow late elective removal, but it may contribute migration at higher rates compared to partially covered or non-covered stents $[13,27]$. Choi et al. reported the stent migration as 15 of $22(68.2 \%)$ patients (all were covered stents). Migration was occurred within two weeks in 8 patients $(53.3 \%)$ and between three to eight weeks in 7 patients $(46.7 \%)$ [13]. Symptomatic improvement continued in 7 of these 15 (46.7\%). Authors suggest that, the stenotic portion will gradually be dilated within one week after stenting and this improves the BPO. On the other hand it may cause stent migration. These results are similar with reports evaluating SEMS in benign esophageal stenosis. Majority of migration occurs within 1 to $8 \mathrm{w}$ in reports $[16,17]$. We observed migration on $3^{\text {rd }}$ and $5^{\text {th }}$ week in our study. A recent report indicated that fixing the covered SEMS with the endoscopic clip is possible and significantly 
diminishes esophageal stent migration [28]. However, reports about the benign diseases have small sample size and there was a need for control group.

Cwikiel et al. studied on pigs for benign esophageal stenosis and experienced that granulation tissue grew and merged with the uncovered surface of SEMS causing the difficulties of stent removal only $1 \mathrm{w}$ after the stenting. The external surface of the SEMS may be dissolved by the effect of biliary or gastric acids resulting in growth [27]. These complications may be prevented with the development of biodegradable new stents [29]. Studies should be implemented with large case series also for other benign and malign pathologies.

In our study, $8 \mathrm{~cm}$ or $12 \mathrm{~cm}$ in length stents were used for pyloric or pyloric+bulbus duodeni obstruction and migration was observed only in two patients $(13.5 \%)$, with a low rate than literature. These patients were presented with a huge gastric dilatation while stenting and had obstructive symptoms during three weeks after stenting. Although an additional SEMS was applied, obstructive symptoms were not resolved and DSGRYGJ was performed in both patients. Sample size in our study is not wide enough however we may suggest that low migration rate may be relevant with appropriate technique and use of proper in length stent. Our technical success rate was $100 \%$.

Tissue ingrowth through the stent wall may complicate the removal of both covered and uncovered stents. Removal is required as soon as the obstructive symptoms begin. However, we do not have a precise guideline for the timing of removal. Accompanied by the reported studies we can suggest removing the stents 6 to $8 \mathrm{w}$ after the stenting [13].

Heo et al. observed the migration of partially covered SEMS in two of ten BPO patients. EBD had been performed previously in these two patients. EBD may dilate the strictured pyloric tissue and thereby cause the migration [22]. Because of low migration rates partially covered stents may be more appropriate and effective in BPO [22]. Technical success and rapid symptom recovery rates were reported as $100 \%$. In addition, $90 \%$ of patients were asymptomatic with a median of 11 (4 to 43) months follow-up time [22]. In our study $80 \%$ of patients were found as asymptomatic during a 42.7 months follow up time. In another BPO study, partially covered SEMSs were applied to five times failed EBD performed patients and obstructive symptoms were improved during the 1 st year [30]. In our study, failed EBD was performed on six patients. GOOSS score was improved from 1 to 3 after stenting in these patients. SEMSs could be a preferable alternative in also patients with failed EBD.

In a wide scaled meta-analysis of SEMSs for malignant pyloric obstruction Sagar reported that, there was a significant clinical success in a short time from stenting to oral intake. Also morbidity rates were lower than surgery [8]. This is an effective approach for palliation. All the previous studies have small sample size and it was concluded that stenting for BPO is an effective treatment modality. However further wide scaled comparative studies should be performed to reinforce these idea $[10,13]$.

It is postulated that better symptom management could be obtained by gradual and continuous dilatation with SEMS in the stenotic segment. The results show that there are low rates of recurrences after stenting and it reduces the need for further invasive procedures. Moreover, SEMS appears as safer and well tolerated method with low complications. Past experiences and reports on malignant strictures also encourage surgeons to use SEMS in benign pathologies. However, the number of studies on literature is not too much satisfactory yet for BPO.

In our study, sample size is small and follow up time is not enough to evaluate the efficacy. Another limitation is that our study was retrospective. Prospective studies will be much more expressive to assess the patients improvement. Further studies should be performed to clarify these limitations. Also the optimal indications and timing of stent removal for BPO should be clarified in further reports.

\section{Conclusion}

Endoscopic stenting with covered SEMSs in benign pyloric obstructions has the advantages of low complications with patient compliance. Rapid improvement in obstructive symptoms can be obtained with successful implementation. Some complications of migration and restenosis have been reported, but newly developed stents are expected to over heal these challenges. Reports in the literature indicate that SEMS has already been placed as an alternative method for either benign or malign pyloric stenosis. However prospective, widescaled and comparative studies will be beneficial to strengthen these suggestions.

\section{Ethics Committee Approval}

Ethics committee approval was received for this study from the ethics committee.

\section{Informed Consent}

Written informed consent was obtained from patients and their parents who participated in this study.

\section{Conflict of Interest}

There is no conflict of interest in this study.

\section{Financial Disclosure}

This study has received no financial support.

\section{References}

1. Kozoll DD, Meyer KA. Obstructing gastroduodenal ulcer, symptoms and signs. Arch Surg 1964; 89: 491-498. 
2. Benjamin SB, Cattau EL, Glass RL. Balloon dilation of the pylorus: therapy for gastric outlet obstruction. Gastrointest Endosc 1982; 28: 253-254.

3. Kochhar R, Sethy PK, Nagi B, Wig JD. Endoscopic balloon dilatation of benign gastric outlet obstruction. J Gastroenterol Hepatol 2004; 19: 418-422.

4. Cherian PT, Cherian S, Singh P. Long-term follow-up of patients with gastric outlet obstruction related to peptic ulcer disease treated with endoscopic balloon dilatation and drug therapy. Gastrointest Endosc 2007; 66: 491-497.

5. Lam YH, Lau JY, Fung TM, Ng EK, Wong SK, Sung JJ, Chung SS. Endoscopic balloon dilation for benign gastric outlet obstruction with or without Helicobacter pylori infection. Gastrointest Endosc 2004; 60: 229-233.

6. Jaffin BW, Kaye MD. The prognosis of gastric outlet obstruction. Ann Surg 1985; 201: 176-179.

7. Hosono S, Ohtani H, Arimoto Y, Kanamiya Y. Endoscopic stenting versus surgical gastroenterostomy for palliation of malignant gastroduodenal obstruction: a meta-analysis. J Gastroenterol 2007; 42: 283-290.

8. Sagar J. Colorectal stents for the management of malignant colonic obstructions. Cochrane Database Syst Rev 2011; 11: 007378 .

9. Adler DG, Baron TH. Endoscopic palliation of malignant gastric outlet obstruction using self-expanding metal stents: experience in 36 patients. Am J Gastroenterol 2002; 97: 72-78.

10. Dormann AJ, Deppe H, Wigginghaus B. Self-expanding metallic stents for continuous dilatation of benign stenoses in gastrointestinal tract - first results of long-term follow-up in interim stent application in pyloric and colonic obstructions. Z Gastroente 2001; 39: 957-960.

11. Binkert CA, Jost R, Steiner A, Zollikofer CL. Benign and malignant stenoses of the stomach and duodenum: treatment with self-expanding metallic endoprostheses. Radiology 1996; 199: 335-338.

12. Song HY, Shin JH, Yoon CJ. A dual expandable nitinol stent: experience in 102 patients with malignant gastroduodenal strictures. J Vasc Interv Radiol 2004; 15 : 1443-1449

13. Choi WJ, Park JJ, Park J. Effects of the temporary placement of a self-expandable metallic stent in benign pyloric stenosis. Gut Liver 2013; 4: 417-422.

14. Acunas B, Poyanli A, Rozanes I. Intervention in gastrointestinal tract: the treatment of esophageal, gastroduodenal and colorectal obstructions with metallic stents. Eur J Radiol 2002; 42: 240-248.

15. Laasch HU, Martin DF, Maetani I. Enteral stents in the gastric outlet and duodenum. Endoscopy 2005; 37: 74-81.

16. Cheng YS, Li MH, Chen WX. Comparison of different intervention procedures in benign stricture of gastrointestinal tract. World J Gastroenterol 2004; 10: 410-414.

17. Song HY, Park SI, Do YS. Expandable metallic stent placement in patients with benign esophageal strictures: results of long-term follow-up. Radiology 1997; 203: 131-136.

18. Laasch HU, Martin DF, Maetani I. Enteral stents in the gastric outlet and duodenum. Endoscopy 2005; 37: 74-81.

19. ASGE Standards of Practice Committee, Banerjee S, Cash BD, Dominitz JA, Baron TH, Anderson MA, BenMenachem T, Fisher L, Fukami N, Harrison ME, Ikenberry SO, Khan K, Krinsky ML, Maple J, Fanelli RD, Strohmeyer L. The role of endoscopy in the management of patients with peptic ulcer disease. Gastrointest Endosc 2010; 71: 663-668.

20. Kuwada SK, Alexander GL. Long-term outcome of endoscopic dilation of nonmalignant pyloric stenosis. Gastrointest Endosc 1995; 41: 15-17.

21. Perng CL, Lin HJ, Lo WC. Characteristics of patients with benign gastric outlet obstruction requiring surgery after endoscopic balloon dilation. Am J Gastroenterol 1996; 91: 987-990.

22. Heo J, Jung MK. Safety and efficacy of a partially covered self-expandable metal stent in benign pyloric obstruction. World J Gastroenterol 2014; 20: 16721-16725.

23. Kang HW, Kim SG. Upper gastrointestinal stent insertion in malignant and benign disorders. Clin Endosc 2015; 48: 187-193.

24. Jeurnink SM, van Eijck CH, Steyerberg EW. Stent versus gastrojejunostomy for the palliation of gastric outlet obstruction: a systematic review. BMC Gastroenterol 2007; 7: 18 .

25. ASGE Standards of Practice Committee, Fukami N, Anderson MA. The role of endoscopy in gastroduodenal obstruction and gastroparesis. Gastrointest Endosc 2011; 74: 13-21.

26. Laasch HU, Martin DF, Maetani I. Enteral stents in the gastric outlet and duodenum. Endoscopy 2005; 37: 74-81.

27. Cwikiel W, Willén R, Stridbeck H, Lillo-Gil R, von Holstein CS. Self-expanding stent in the treatment of benign esophageal strictures: experimental study in pigs and presentation of clinical cases. Radiology 1993; 187: 667-671.

28. Vanbiervliet G, Filippi J, Karimdjee BS. The role of clips in preventing migration of fully covered metallic esophageal stents: a pilot comparative study. Surg Endosc 2012; 26: 53-59.

29. Tanaka T, Takahashi M, Nitta N. Newly developed biodegradable stents for benign gastrointestinal tract stenoses: a preliminary clinical trial. Digestion 2006; 74 : 199-205.

30. Park S, Chun HJ, Keum B. Successful salvage treatment of peptic duodenal stenosis with repeat insertion of selfexpanding stent after failed balloon dilation. Endoscopy 2011; 43: 187-188.

\section{*Correspondence to}

Gokhan Demiral 
Covered self-expandable metallic stents in benign pyloric obstruction: long term results

General Surgery Department

Turkey

Recep Tayyip Erdogan University 